\title{
The triangle of effective education implemented for Theology
}

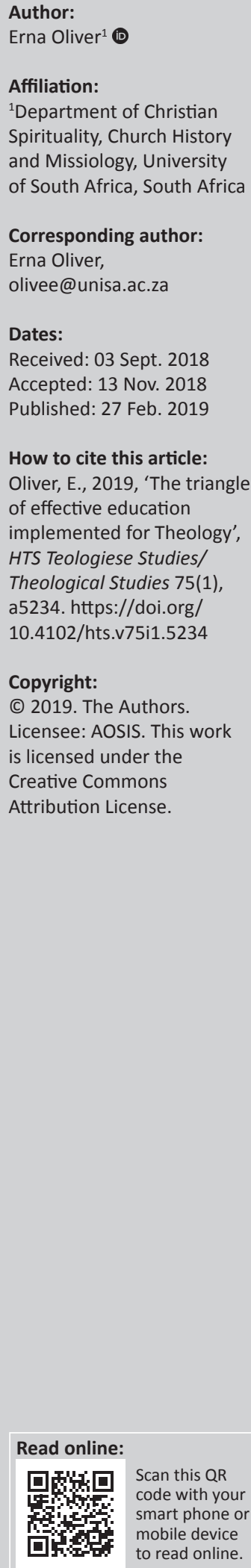

\begin{abstract}
Higher education in general, and more specifically in the South African environment, is under pressure to transform. Although learning is often seen as the main focal point, the education process consists of three equally important pillars that form the triangle of effective education that fits within the intersection of the spheres of the community of inquiry framework. The basic pillars expand to student-centred teaching, blended learning and transformative assessment. This study is a short explanation of how these three pillars form a basic framework for effective theological training. This is a qualitative study, using a philosophical and analytical research design and illuminative evaluation as research method. This is a model for effective higher education in Theology. The triangle of effective education is formed by student-centred teaching, blended learning and transformative assessment. The model fits into the intersection of the spheres identified by the community of inquiry framework of Garrison, Anderson and Archer.
\end{abstract}

\section{Introduction}

Higher education is shifting in terms of focus, philosophy, methodology and delivery systems (Wells 2018:1), and the 2016 new media consortium (NMC) report calls the problem of keeping higher education relevant a 'wicket' challenge (Johnson et al. 2016:32). Nussbaum (2016:2) states that there is a worldwide crisis in education because of the focus shift to economic growth and the neglect of the humanities and arts, which provide the skills and knowledge needed to keep democracies vigorous (Nussbaum 2016:xvii).

As society changes, educational practices should change likewise (cf. Pokorny \& Warren 2016:1), and it seems as if this need for change forms part of the aforementioned problems that higher education is facing. Some of the methods and models of teaching, learning and assessment that were introduced when universities first developed, like lecturing, are sometimes still used as the only tuition strategy despite the availability of other tools and media that can enhance education practices. At the beginning of the century, Passmore (2000) lamented that it took overhead projectors 40 years to move from bowling alleys to classrooms. The quote by Bates (2010:22) of a vice-chancellor, who said that 'universities are like graveyards - when you want to move them, you do not get much help from the people inside', further emphasises two sides of the problem: on the one hand, educators often do not experiment with and implement technology as a helpful tool in educational environments, and on the other hand institutional stakeholders do not create or sustain favourable conditions for innovation and development. However, educational change cannot happen successfully through a single technological paradigm shift. It can only be achieved through the adaptation of and commitment to a process of continual change at all levels through constant testing, implementing and adjusting (cf. Ice 2010:158).

In the South African environment, the programme qualification mix is adjusted to address demands and provide qualifications in niche and developing areas but, sadly, often indiscriminately following international trends. The past few years have been traumatic for all who are linked to the higher education sector. The widening gap between basic education (Modisaotsile 2012) and higher education, together with the pressure to produce more graduates who are qualified for an unknown future where job markets are unstable and evolving, are forcing higher education to take on responsibilities beyond focussing only on teaching subject-specific course content. Institutions are expected to provide increasing numbers of bridging courses and support structures to assist under-prepared students to become successful in their studies and career paths while accommodating ever-increasing numbers of students to supply in the growing demand for

Note: OEH: The Online Educated Human: Teaching values, ethics, morals, faith and religion at a distance, sub-edited Ignatius Gous (UNISA). 
higher education. The \#RhodesMustFall and \#FeesMustFall campaigns and their repercussions (cf. Jansen 2017; Venter 2016:1) not only stress economic issues but also shine the spotlight on the levels of inequality and fragmentation prevalent in South African society, and the push towards decolonised and Africanised curricula.

In line with the developments in the humanities, the space allocated to Theology in higher education is shrinking (Buitendag 2014; Mouton 2008:432) and even being targeted to be removed from universities (Loughlin 2009; Wilkinson 2007). However, Harrison (2009) argues that theological issues still remain important in contexts such as education, epistemology and philosophy, all of which are influencing science and society in general. Miller (2008:4) also acknowledges the hybrid and multifaceted character of society, where religion and faith dominate parts of life and culture. In South Africa, there is still a need for theological training and academic reflection on theological issues as more than $80 \%$ of the South African population claims to be Christian (Statistics South Africa 2004:28). The need for graduates who can voice Christian responses to public issues and act as positive agents of change is growing as the social, economic and political environment in South Africa is deteriorating. Through functioning in the epicentre of society (Tracy 2002), the importance of Theology as an active voice in the public sphere (Mouton 2008) to promote change, renewal and transformation is clear (e.g. Theology played a major role in both establishing and demolishing apartheid).

It is beyond the scope of a single article to focus on all of the aforementioned aspects and their complex effects on the higher education environment in South Africa. All of these issues, however, do have an impact on the main focus of this research, namely to propose a model for teaching Theology by promoting student-centred teaching through blended learning and transformative assessment.

This article proposes a model for structuring higher education for theological students that could assist academics with practical pointers towards curriculum design with long-term positive outcomes that go beyond specific subject knowledge and skills. It may also ensure that attending a higher education institution is not only about obtaining a qualification but indeed an experience of growth and development that results in positive and active changes in thinking patterns, world views and behaviour. This will ensure that graduates in Theology become active, productive and positive custodians of knowledge and skills, capable of thriving in the fastchanging and challenging world. They should be able to transfer knowledge and skills in such ways that the communities they live and work in can also benefit from their education.

Firstly, a few comments are made regarding the method used to do the research and to construct the article, followed by a short description of the concept of effective higher education and how the community of inquiry framework (Garrison, Anderson \& Archer 2000) can be used to accommodate the triangle of effective education. The main focus falls on an explanation of the proposed triangle of effective education as a foundational model for making a positive impact on the growth and development of students at an open distance university. In this description it will be shown how the model can enhance and promote the positive impact of theological education in the South African context.

\section{Research method}

Illuminative evaluation was developed by Parlett and Hamilton (1972) to investigate an educational programme through observation, inquiry and explanation. The background study (observation) showed that higher education is experiencing changes and challenges in response to the changes and demands of the 21st-century society. In the South African context, both higher education and Theology need to adjust to the African context. The identified pillars (identified and selected through inquiry) around which effective education must be built are the three equally important aspects of student-centred teaching, blended learning and transformative assessment. This triangular basis for effective education fits in within the community of inquiry theoretical framework. Finally, this research serves as a recommendation (explanation) of how theological education can use and implement the model.

\section{The concept of effective education}

Fraser (1994:104) defines effectiveness in higher education as measuring the match between stated outcomes (of a course or a module or a programme) and the achievement of these goals. In line with this, UNESCO (Vlãsceanu, Grünberg \& Pârlea 2004:37) sees effectiveness in higher education as the achievement of specific educational goals and requirements, based on a culture of evidence.

Hunt, Chalmers and Macdonald (2013:22) define effective university teaching as a holistic practice of teaching that includes an understanding of how students learn in an inclusive and supportive learning environment. It also focuses on curriculum development, assessment and feedback to students, as well as scholarship, reflective practices and quality assurance.

Bransford, Brown and Cocking (2000:153) explain that effective education should be student-centred, assessmentcentred, competency-centred and community-directed, thus impacting on the way educators teach, the content that is taught, as well as the long-term and indirect consequences for both graduates and those they are interacting with. The ultimate goal of providing effective higher education is to assist students in becoming 'all they can be' (Cross 2010:48). Students must experience progressive behavioural change (Mayer-Mihalski \& DeLuca 2009) and develop into lifelong, self-directed learners who are able to implement and transfer their knowledge and skills to others, thus becoming responsible and active citizens (Oyler 2012:8). Effective education should enable students to become independent 
learners, increase their motivation levels, improve their success rates and build their confidence to turn them into lifelong learners.

The concept of effectiveness in higher education includes all aspects of the educational process normally labelled 'teaching and learning', which also includes assessment. In order to emphasise the importance of assessment to the educational process, it is helpful to list it more explicitly alongside the term 'teaching and learning'. Effective education is therefore a creative combination of teaching, learning and assessment that results in positive learning outcomes that are in line with the set goals of the programme (Huerta-Macias 1995). These goals not only include the acquirement of knowledge, skills, competencies and capacities ${ }^{1}$ but also promote changes in behaviour, attitudes, values and world views. Effective education can be achieved when all of these aspects are given the correct scope by educators, students and higher education institutions.

Effective learning should occur at the intersection of the three spheres of the community of inquiry framework, developed by Garrison et al. (2000). This triangular space should be the focus area of both the educational activities and the support structures provided by higher education to ensure positive results (see Figure 1). This add-on expansion model of the community of inquiry framework identifies the three major pillars that should form the foundation for effective education processes and also includes a few practical examples for teaching Theology.

\section{The triangle of effective education}

Effective education links the three equally important aspects of education together into a triangle that should form the foundation of curriculum development and teaching practices at higher education institutions. The broad base of the triangle is formed by teaching and learning, with assessment linking these two aspects at the pinnacle to lock the three corner posts into a firm construction, as assessment bridges the gap between teaching and learning (Nasab 2015:165). Effective education aims to develop and build capabilities and competencies, knowledge and skills, as well as attitudes and behaviour that are expanding into the lives, worldviews and actions of students. This basic triangle of effective education, especially in an open distance learning environment, expands to focus on student-centred teaching, blended learning and transformative assessment (see Figure 2). The model will show how these three pillars support each other and the focus of the following discussion will be on practical suggestions to enhance effective education practices. These suggestions are by no means exhaustive. They are, to the contrary, initial basics that should be incorporated in the curriculum design of theological subjects in order to address some of the current issues in the South African higher education system.

1.'Competency' is the proven ability of acquiring knowledge and skills, while "capacity' is the learner's confidence in his or her competency and, as a result, the ability to is the learner's confidence in his or her competency and, as a result, the ability to
take appropriate and effective action in both familiar and unfamiliar and changing take appropriate and effect
settings (Cairns 2000:1).

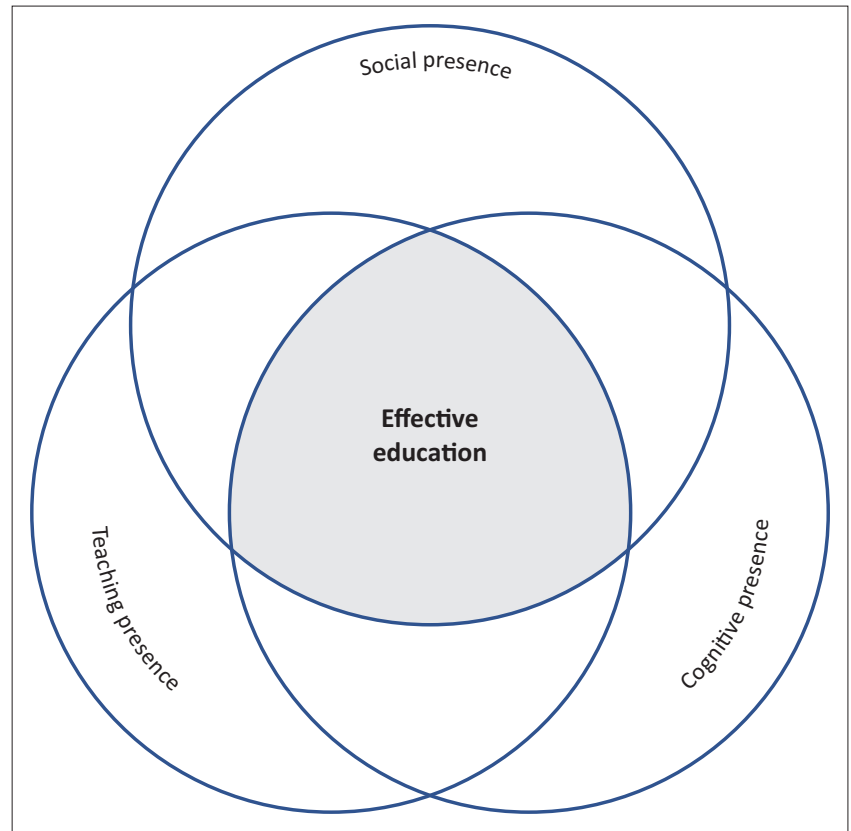

Source: Adapted from Garrison, D.R., Anderson, T. \& Archer, W., 2000, 'Critical inquiry in a text-based environment: Computer conferencing in higher education model', The Internet and Higher Education 2(2-3), 87-105. https://doi.org/10.1016/j.iheduc.2004.02.001

FIGURE 1: The community of inquiry framework of Garrison et al. (2000) provides a practical setting for the triangle of effective education.

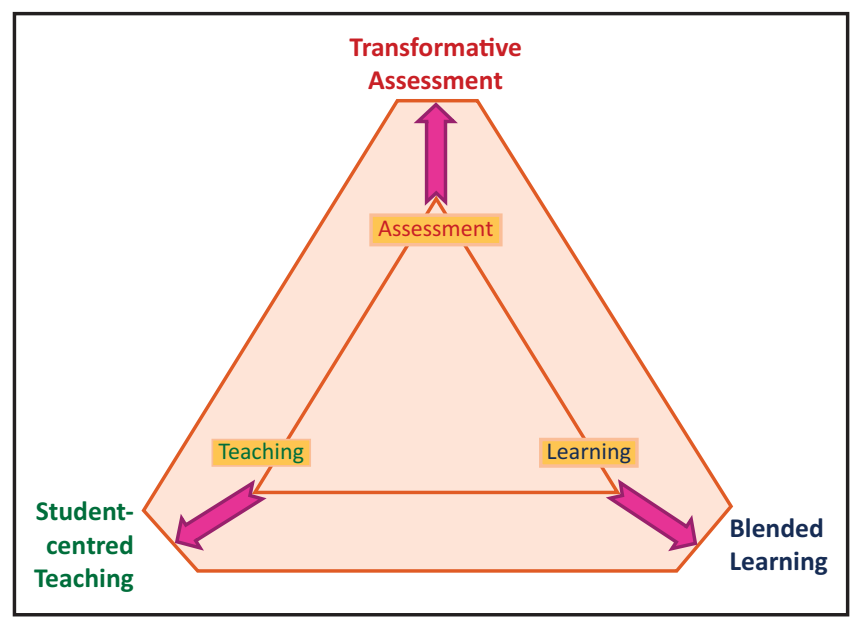

FIGURE 2: The corner posts of effective education are student-centred teaching, blended learning and transformative assessment (cf. Oliver 2015:4).

\section{Student-centred teaching}

The biggest challenge for successful student-centred teaching in the South African environment is the student population itself. The student pool is diverse and unequal. Variations in educational standards, language competencies, economic means, access to and the use of technology will presumably keep the student community diverse and unequal for years to come.

Inadequate and deteriorating teacher-centred basic education challenges higher education to expand its operations in order to meet students where they are. Higher education must provide a path towards student-centred teaching, where students are active and take responsibility for selfdirected development paths; blended learning, where they need to navigate successfully through multimedia, information overload and different learning modes; and 
transformative assessment, where it is no longer sufficient to memorise information from textbooks and study guides to obtain a qualification.

Although students are the main stakeholders in higher education, there are at least two other major roleplayers that are key factors in providing effective student-centred teaching: both the institutions and the lecturing staff need to be committed to the concept of student-centredness to ensure that teaching focuses on addressing the needs, talents, career paths and long-term growth and development of individual students. The University of South Africa (Unisa) defines student-centredness as the principle of systematically recognising students' worldviews and lived experiences as well as prior learning in the development of curricula that will allow students to reach their learning objectives and aspirations (Unisa 2016:6). Unfortunately, including statements like these in policy documentation does not per se implement student-centredness into the curriculum, teaching practices or practical administration of the university. The policy also does not take into account issues such as other university policies (e.g. policies on access and openness), government policies and ideologies, economic factors and international rankings that normally do not include the aspects of teaching and learning (Siwinski \& Holmes 2018). The concept of student-centred teaching, to be effective, must be absorbed into the culture, structure, management and business model of the organisation. Research and activism are needed to transform South African institutions to fully become student-centred.

Academics are subject specialists and often uncertain about course design using unfamiliar strategies and theories and technology-based communication tools. Again, research, activism and a choice to specialise in teaching with adequate training opportunities, as well as proper recognition for excellence in the field of student-centred teaching, can enhance academics' abilities and focus on effective studentcentred teaching: 'Effective teaching is an outcome of decision-making that arises from knowing why you are doing what you are doing. Such decision-making starts and finishes with students' (Hunt, Chalmers \& Macdonald 2013:22). With the main focus on the needs and success of students, academics and higher education institutions should implement additional programmes that cater for the unique South African circumstances.

Academic literacy is the suggested path that, intertwined with subject-specific education, must be constructed to guide student-centred teaching in a progressive manner from firstyear level to graduateness and eventually to ensure that graduates become positive agents of change and responsible global citizens. Whitelaw et al. (2010:6) define academic literacy as the ability to read, write, understand, analyse, interpret, create and communicate in a formal scholarly context. It involves being capable of critical and independent thought, being able to work independently and knowing how to acknowledge the work of others. Academic literacy thus fans out into language proficiency, critical thinking skills, digital literacy, research literacy and subject-specific literacy. Ensuring that these five competencies and capacities are developed concurrently with subject knowledge and skills will ensure that student-centred teaching becomes more successful.

Firstly, language proficiency (oral, written, auditory and visual) is required to effectively understand, summarise, analyse, evaluate, compare, contrast and synthesise information from different sources. It is needed to communicate newly constructed content and ideas in acceptable academic language and syntax to both peers and general audiences. It is therefore crucial that teaching should be done in such a way that students understand. Theology has an enormous amount of professional terminology that needs to be defined in glossaries and also to be translated to indigenous languages as students need to use these concepts in their native languages and their faith communities.

Secondly, critical thinking is a complex concept, which Moore (2013) describes as consisting of the following seven elements: judgement (including the ability to recognise assumptions and biasness of both the students themselves as well as those of others), a sceptical and provisional view of knowledge, simple originality, careful and sensitive reading of texts, rationality, the adopting of an ethical and activist stance, and self-reflexivity. Theology students must be guided and coached on debating and defending their views on doctrinal, ethical, faith-related and social issues. One way of doing this is through implementing critical thinking to seek solutions for real-life theological issues (e.g. defending ancestor veneration as part of the Protestant religion).

Thirdly, students must be taught to be digitally literate. The term 'digital literacy' was coined by Gilster in 1997. It incorporates the skills and competencies needed to access and interact with information embedded in digital sources (Jaeger et al. 2012). These skills include cognitive, motoric, sociological and emotional abilities (Eshet 2012). Koltay (2011) identifies four core competencies: internet searching, hypertext navigation, knowledge assembly and content evaluation. In the constructionist ${ }^{2}$ environment, the ability to create and communicate opinions, questions, information and knowledge on different media platforms also forms part of digital literacy. Oloyede (2011:75) explains that computer and information and communication technology (ICT) literacy is not limited to an individual's ability to operate computers and other electronic devices, but it also includes the person's ability to solve his or her personal, professional and community problems through the deployment of his or her expertise and experience in computer and ICT-related issues. Technology is not a substitute for learning; it provides tools through which education can be enhanced. Digital and electronic technology is a useful addition to the toolbox of education, next to language, writing and the products of the printing press.

2.In the constructivist approach, teaching is based on a partnership: a dialogue between educator and student on the one content on the other. The goal is not to interpret the material for the students but rather to provide opportunities for the students to formulate their own questions, to form their own interpretations and opinions of contrasting schools of thought, and 'to produce their own texts' (Higgs, Van Niekerk \& Van Wyk 2010:136). 
Fourthly, educators must ensure that students are able to do proper research. McGreger (2018:6) defines research literacy as the ability to conduct and report on research. Students must be able to locate, interpret, evaluate and use information effectively while heeding protocol regarding intellectual property and rules on plagiarism. Information literacy forms part of research literacy, as students must recognise the value of information and be able to filter it in order to make informed choices and changes in their personal, academic and professional lives. Another part of research literacy is media literacy, which in the past referred to people's ability to read and write but currently is expanded to interaction with text, sound and images, where the medium and the message fuse into 'interactive, multimodal information spaces'(Gonzalez, Cranitch \& Jo 2000:90).

Lastly, subject-specific literacy enables students to become familiar with subject-related terminology, philosophy, methodology, history and practices. The theological department of Northwest University defines theological literacy as the ability to formulate and articulate a Christian worldview based upon and derived from the scriptures and with some awareness of the way the church has formulated such ideas throughout its history (Perkins 2011). To this must be added the ability to fully adopt the Christian lifestyle and become active agents of positive change based on one's convictions and faith.

Teaching academic literacy is most effective when situated within a specific discipline or department (Pokorny \& Warren 2016:7). It must start with diagnostic assessment disclosing to each student what his or her knowledge and skill levels are. Different routes, based on the results of the diagnostic evaluations, should guide students to successfully complete basic levels in each module or course where scaffolded tasks must create sufficient opportunities for students to become familiar with and incorporate knowledge and skills gained into their lives in such a way that they are able to advance to the level of graduateness.

Similar to the proposed triangle of effective education, which places teaching and learning together on the bottom axes of the triangle, other scholars also link the components of student-centeredness and blended learning together and advocate that this link could enhance good practice in the higher education environment (Garrison \& Kanuka 2004; Pallof \& Pratt 2011).

\section{Blended learning}

Blended learning is mostly seen as either a combination of face-to-face and online teaching activities or as a combination of printed and electronic texts used as learning resources. It can also be interpreted as an umbrella term that describes the complex ways in which people learn, unlearn and relearn in all aspects and levels through all stages of life. The development of electronic and digital technology enables education (teaching, learning and assessment) to happen anywhere and anytime, through a wide variety of activities,

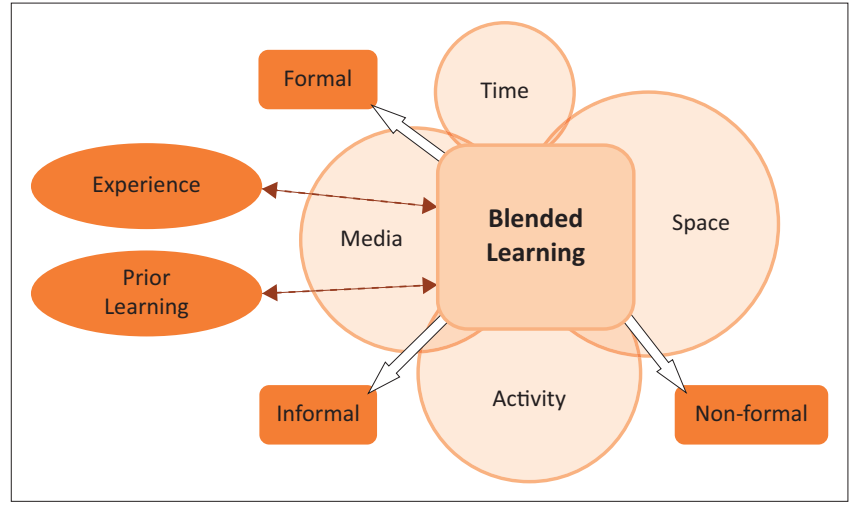

FIGURE 3: Blended learning is complexed and layered (personal design).

all of which form part of blended learning (see Figure 3).The size and overlaps of the four basic components of time, space, activity and media (Littlejohn \& Pegler 2007) vary from person to person. The modes in which learning take place (formal, informal and non-formal) are also individually structured, while each individual student has unique experience and prior learning.

Learning literacy, linking with academic literacy, should start with an introduction to the complex nature of blended learning. Both students and educators on the one hand and the institutions (management, administration, policies and activities) on the other hand must understand the complexity of blended learning and its advantages for flexible learning opportunities in higher education, especially in an open and distance learning environment.

Learning literacy must also focus on the aspect of metalearning as awareness and understanding of the concept of learning and taking control of one's learning (Biggs 1985). Students must be aware of and understand the learning expectations of specific tasks, modules and programmes. They must be able to answer the question of why they are learning Theology and take responsibility for their own learning. A student's learning approach consists of his or her ideas and notions about learning, his or her epistemological beliefs, level of academic literacy and learning processes or journeys. Diagnostic evaluation should enable students to identify their learning approaches and then, through scaffolded engagement, to adjust, expand and improve their individual learning approaches to successfully align them with learning tasks and learning goals in the different disciplines and subject fields.

Blended learning, if understood in its comprehensive and layered structure and implemented to include and explore as many options as possible, can provide students and educators with choices and flexibility in the whole educational process, while it also offers increasing and expanding opportunities for recognition of prior learning and learning outside formal structures and for converting these into formal qualifications (especially in the field of Theology within the South African context). The multiple means of engagement with educators, learning content and fellow students can serve as motivation for learning and success (Hall \& Stahl 2006:19). 
Learning is regarded as the main purpose of education, but assessment determines if learning did occur and if the student is able to apply the learning through cognitive and transferable skills. Therefore, the third pillar of effective education, binding teaching and learning into a triangle, is transformative assessment.

\section{Transformative assessment}

Teaching staff often see assessment as a subdivision of teaching and use it as a grading tool to classify and/or compare students and groups of students with each other (Huerta-Macias 1995:8), while students often use assessment criteria as filters for learning (Gibbs 2006:25). It is therefore important to understand that assessment is an equal partner in the educational process, linking teaching and learning together into a triangle that forms the foundation of a successful educational process.

Effective assessment, according to Blumberg (2014:44), is structured as learning events that enable students to recognise and monitor their own progress and development. It also provides students with opportunities to show that they are able to think and act in responsible, creative and innovative ways through using higher cognitive skills. Assessment for successful learning evaluates the student's ability to demonstrate what they can do with the gained knowledge and skills or to demonstrate how, why and to what extent the learning changed their opinions, behaviour or values, as well as how this will impact on their future development and actions. Assessment outcomes must determine both academic success and life beyond and outside the formal educational environment through various methods and focus areas to reveal change, growth and increasing degrees of integration over time (ARG 2002).

Transformative assessment is the students' ability to demonstrate what they can do and create with the knowledge and insight gained from the learning process, on the one hand, and their ability to prove that change as the ultimate goal of education did occur through the learning process, on the other hand. Alternative assessment, which is gaining momentum through the availability of technology, is often focused on what students actually do and create as a result of their learning. This is already a huge step forward from traditional venue-based, timed tests and examinations where students regurgitate information from textbooks and class notes without showing evidence of deep learning or change.

Transformative and alternative assessment provides the student with choices and flexibility on how to present the evidence of achievement of the learning goals. The choice involves the form and content provided in order to answer questions or perform tasks set to demonstrate the achievement of learning objectives. Transformative assessment focuses on the abilities and strengths of students, and even failure can be turned into opportunities to learn and grow through the learning process and not as a final outcome (Educause learning initiative 2014). The aim of such assessment is to track an individual student's growth and development in all aspects and divisions of the course or programme over a period of time. It provides opportunities for students to show that they are able to think and act in responsible, creative and innovative ways and change their behaviour and values accordingly. It enables students to become independent, build their confidence, increase their motivation levels and improve their success rates, and it aids in eventually turning graduates into lifelong learners. Transformative assessment promotes active learning and is very specific, focusing on specific learning outcomes.

In alternative assessment models, as the first step towards transformative assessment, there are multiple possible correct answers. Each student has the opportunity to react to and answer the assessment question or task in the way he or she finds it appropriate. This could mean that no two answers are the same. Students are not bound to venues, written reports and time limits and can compile and submit their work on different media, at any time and from anywhere.

Traditional assessment methods can be exchanged for creative alternative and transformative assessment methods that match the demands and expectations of all stakeholders (educators, students and the corporate world), to ensure that graduates are competent and capable to take on the challenges of life and work in the information-based network society of the 21st century (Floridi 2014).

Alternative and transformative assessment is a perfect fit for student-centred teaching and blended learning, because it provides both educators and students with choices and flexibility; the use of digital and electronic technology, in addition to traditional educational tools such as language, writing and printed material, allows for creativity and innovation and caters for student diversity and unique preferences. The social nature of education and the role of collaboration and discourse are recognised as important aspects of student development and can easily be incorporated into student-centred teaching, blended learning and transformative assessment.

Although it is widely proclaimed that change should be the ultimate goal of education, ${ }^{3}$ transformation and change in behaviour, opinion, thought patterns and values are seldom evaluated in higher education in general and in Theology courses and programmes. Theology has relatively small student numbers and the student profile of this group is different from that of the university (Oliver 2012:167). This opens the door for alternative and transformative assessment.

In Theology, emphasis is shifting towards assisting students to become positive change agents as an important assessment outcome. A change agent is a person whose presence and/or thought processes and actions cause an alteration from the traditional or conventional way of handling or thinking

3.Buscaglia (n.d.) states that the result of true learning is change, while Piaget (cf. Duckworth 1964:496) indicates change as the goal of education, and Mandela (n.d.) states that the world can be changed through education as a 'powerful weapon'. 
about a problem or a controversial issue. In Theology, another dimension is added to the concept of change agency, namely change through faith. Faith integration is the process of combining the Christian faith and religious experience with the rest of one's life experiences (Cafferky 2012), while education is structured in such a way that the student is motivated to not only gain knowledge and skills but also to instigate positive change in the community through the transfer of gained knowledge, skills and competencies. People living in the 21st century are experiencing the move towards multiple citizenships (cf. Tickle 2012).Therefore, identifying with the Christian faith must - also like in the 1st century convey visible and sustainable positive change, especially in South Africa, where long-term positive transformation of actions, behaviour and value systems is needed.

\section{Conclusion}

Undoubtedly, higher education is constantly changing, and in the South African context the demand for change erupted in unrest and violence with major economic repercussions for the whole country.

This article proposes an educational model for effective higher education by recognising the three equally important pillars of education and expanding them into student-centred teaching, blended learning and transformative assessment. This triangle of effective education model functions as an expansion of the Community of inquiry framework. The model is presented for theological teaching. It provides practical pointers towards curriculum design where the focus is on student-centred teaching with the help of blended learning and transformative assessment. Academic literacy development is identified as the way to actively engage with student-centred teaching. The unique circumstances and abilities of individual students can be addressed, while blended learning, with its layered composition and complexity, can also be accommodated. Transformative assessment will assist students to become active citizens who can advocate for Christianity and its practical implications in the public sphere and at all levels of society.

\section{Acknowledgements Competing interests}

The author declares that she has no financial or personal relationships which may have inappropriately influenced her in writing this article.

\section{References}

Assessment Reform Group (ARG), 2002, Assessment for learning: 10 principles. Research-based principles to guide classroom practice, viewed 05 September
2017, from http://www.hkeaa.edu.hk/DocLibrary/SBA/HKDSE/Eng_DVD/doc/Afl_ principles.pdf

Bates, T., 2010, 'New challenges for universities: Why they must change', in U-D. Ehlers \& D. Schneckenberg (eds.), Changing cultures in higher education. Moving ahead to future learning, pp. 15-25, Springer, Heidelberg.

Biggs, J.B., 1985, 'The role of metalearning in study processes', British Journal of Educational Psychology 55(3), 185-212. https://doi.org/10.1111/j.2044-8279.1985. tb02625.x

Buitendag, J., 2014, 'Between the Scylla and the Charybdis: Theological education in the 21st century in Africa', HTS Theological Studies 70(1), art \#2855, 5 pages. https://doi.org/10.4102/hts.v70i1.2855
Blumberg, P., 2014, Assessing and improving your teaching: Strategies and rubrics for faculty growth and student learning, Jossey-Bass, San Francisco, CA.

Bransford, J.D., Brown, A.L. \& Cocking, R.R. (eds.), 2000, How people learn: Brain, mind, experience, and school, Expanded edn., National Academy Press, Washington, DC.

Buscaglia, L., n.d., Quotes, viewed 05 September 2017, from www.goodreads.com/ author/quotes/27573.Leo_Buscaglia

Cafferky, M.E., 2012, Management: A faith-based perspective, Pearson Education, Upper Saddle River, NJ.

Cairns, L., 2000, The process/outcome approach to becoming a capable organization, Australian Capability Network Conference, Sydney, pp. 1-14.

Cross, J., 2010, “"They had people called professors...!" Changing worlds of learning: Strengthening informal learning in formal institutions', in U.-D. Ehlers \& D. Schneckenberg (eds.), Changing cultures in higher education. Moving ahead to future learning, pp. 43-54, Springer, Heidelberg.

Duckworth, E., 1964, Piaget rediscovered, The Arithmetic Teacher 11(7), 496-499. https://doi.org/10.1002/tea.3660020305

Educause Learning Initiative, 2014, 7 things you should know about...competency-based education, viewed 05 September 2017, from http://www.educause.edu/library/ resources/7-things-you-should-know-about-competency-based-education

Eshet, Y., 2012, 'Thinking in the digital era: A revised model for digital literacy', in E.B. Cohen (ed.), Issues in informing science and information technology (9), pp. 267-276, Informing Science Press, Santa Rosa, CA.

Floridi, L., 2014, The 4th revolution: How the infosphere is reshaping human reality, Oxford University Press, Oxford.

Fraser, M., 1994, 'Quality in higher education: An international perspective', in D. Green (ed.), What is quality in higher education?, pp. 101-111, Open University Press and Society for Research into Higher Education, Buckingham.

Garrison, D.R., Anderson, T. \& Archer, W., 2000, 'Critical inquiry in a text-based environment: Computer conferencing in higher education model', The Internet and Higher Education 2(2-3), 87-105. https://doi.org/10.1016/j.iheduc.2004.02.001

Garrison, D.R. \& Kanuka, H., 2004, 'Blended learning: Uncovering its transformative potential in higher education', Internet and Higher Education 7(2), 95-105.

Gibbs, G., 2006, 'How assessment frames student learning', in C. Bryan \& K. Clegg (eds.), Innovative assessment in higher education, pp. 23-36, Routledge, New York. Gilster, P., 1997, Digital literacy, Wiley Computer Publishing, New York.

Gonzalez, R., Cranitch, G. \& Jo, J., 2000, 'Academic directions of multimedia education', Communications of the ACM 43(1), 89-95. https://doi.org/10.1145/ 323830.323849

Hall, T. \& Stahl, S., 2006, 'Using universal design for learning to expand access to higher education', in M. Adams \& S. Brown (eds.), Towards inclusive learning in higher education: Developing curricula for disabled students, pp. 67-78, Routledge, Abingdon.

Harrison, P., 2009, 'The full man and foundations of Science', Cambridge University Press, Cambridge.

Higgs, P., Van Niekerk, L.J. \& Van Wyk, B., 2010, 'The role of community in curriculum development for ODL in an African context', Progressio 32(2), 134-144.

Huerta-Macias, A., 1995, 'Alternative assessment: Responses to commonly asked questions', TESOL Journal 5(1), 8-10.

Hunt, L., Chalmers, D. \& Mcdonald, R., 2013, 'Effective classroom teaching', in L. Hunt \& D. Chalmers (eds.), University teaching in focus, pp. 21-37, Routledge, New York.

Ice, P., 2010, 'The future of learning technologies: Transformational developments', in M.F. Cleveland-Innes \& D.R. Garrison (eds.), An introduction to distance
education: Understanding teaching and learning in a new era, pp. 155-164, education: Understandin
Routledge, New York.

Jaeger, P.T., Bertot, J.C., Thompson, K.M. Katz, S.M. \& DeCoster, E.J., 2012, 'The intersection of public policy and public access: Digital divides, digital literacy intersection of public policy and public access: Digital divides, digital literacy,
digital inclusion, and public libraries', Public Library Quarterly 31(1), 1-20. https:// digital inclusion, and public libraries',
doi.org/10.1080/01616846.2012.654728

Jansen, J.D., 2017, As by fire: The end of the South African University, Tafelberg, Cape Town.

Johnson, L., Adams Backer, S., Cummins, M., Estrada, V., Freeman, A. \& Hall, C., 2016 'NMC horizon report: 2016 higher education', 1st edn., The New Media Consortium, Austin, viewed 05 February 2018, from cdn.nmc.org/media/2016-nmc-horizonreport-he-EN.pdf

Koltay, T., 2011, 'The media and the literacies: Media literacy, information literacy, digital literacy', Media, Culture \& Society 33(2), 211-221. https://doi.org/ 10.1177/0163443710393382

Littlejohn, A. \& Pegler, C., 2007, Preparing for blended e-learning, Routledge, New York.

Loughlin, G., 2009, 'Theology in the university', in I. Ker \& T. Merrigan (eds.), The Cambridge companion to John Henry Newman, pp. 221-240, Cambridge University
Press, Cambridge, viewed 13 July 2014, from https://www.dur.ac.uk/theology. religion/staff/profile/?mode+pdetail\&id=2394\&sid=2394\&pdetail=57986

Mandela, N.R., n.d., Brainyquote, viewed 02 January 2018, from https://www. brainyquote.com/quotes/nelson_mandela_157855

Mayer-Mihalski, N. \& DeLuca, M.J., 2009, Effective education leading to behavior change, viewed 05 September 2017, from http://www.paragonrx.com/experience/ white-papers/effective-education-leading-to-behavior-change/

McGreger, S.L.T., 2018, Understanding and evaluating research: A critical guide, Sage, London.

Miller, J., 2008, 'What secular age?', International Journal of Politics, Culture and Society, viewed 12 July 2013 , from http://link.springer.com/article/10.1007/ s10767-008-9037-5/fulltext.htm 
Modisaotsile, B.M., 2012, 'The failing standard of basic education in South Africa', AISA Policy Brief 72(March 2012), 1-7, viewed 13 December 2017, from http:// www.ai.org.za/wp-content/uploads/downloads/2012/03/No.-72.The-Failingwww.ai.org.za/wp-content/uploads/downloads/20
Standard-Of-Basic-Education-in-South-Africa1.pdf

Moore, T., 2013, 'Critical thinking: Seven definitions in search of a concept', Studies in Higher Education 38(4), 506-566. https://doi.org/10.1080/03075079.2011. 586995

Mouton, E., 2008, 'Christian theology at the university: On the threshold or in the margin?', HTS Theological Studies 64(1), 431-445. https://doi.org/10.4102/ htsv64i1.21

Nasab, F.G., 2015, 'Alternative versus traditional assessment', Journal of Applied Linguistics and Language Research 2(6), 165-178.

Nussbaum, M.C., 2010, Not for profit: Why democracy needs the humanities, Princeton University Press, Princeton, NJ.

Oliver, E., 2012, 'Closing gaps in open distance learning for theology students', Acto Theologica 32(2), 162-183.

Oliver, E., 2015, 'Alternative assessment for effective open distance education, unpublished mini-dissertation', M.Ed in ODL, University of South Africa, Pretoria.

Oloyede, S., 2011, 'Computer literacy and ICT literacy: The changing face of literacy', The African Symposium 11(2), viewed 28 April 2018, from https://projects.ncsu. edu/aern/TAS11.2/TAS11.2_70yelekan.pdf

Oyler, C., 2012, Actions speak louder than words: Community activism as curriculum Routledge, New York.

Pallof, R.M. \& Pratt, K., 2011, The excellent online instructor. Strategies for professional development, Jossey-Bass, San Francisco, CA.

Parlett, M. \& Hamilton, D., 1972, Evaluation as illumination: A new approach to the study of innovatory programs, Edinburg University, Edinburg.

Passmore, D.L., 2000, Impediments to adoption of Web-based course delivery, viewed 31 January 2018, from http://train.ed.psu.edu/documents/edtech/edt.pdf

Perkins, L., 2011, What is 'Theological Literacy' and why is it important?, Northwes Centre for Biblical \& Theological Literacy, viewed 28 April 2018, from http:// biblicalliteracy.nbseminary.ca/what-is-theological-literacy-and-why-is-itimportant-2/\#_ftn1
Pokorny, H. \& Warren, D., 2016, Enhancing teaching practice in higher education, Sage, London.

Siwinski, W. \& Holmes, R., 2018, 'What makes a real international university ranking?' University World News. The global window on higher education, $\mathrm{nr}$ 503, 27 April 2018, viewed 28 April 2018, from http://www.universityworldnews.com/article. php?story $=20180425093629732$

Statistics South Africa, 2004, Primary tables, Stats SA, Pretoria.

Tickle, P., 2012, Emergence Christianity: What it is, where it is going and why it matters, Baker Books, Grand Rapids, MI.

Tracy, D., 2002, 'On theological education: A reflection', in R.L. Petersen \& N.M. Rourke (eds.), Theological literacy for the twenty-first century, pp. 13-22, Eerdmans, Grand Rapids, MI

Unisa, 2016, Curriculum policy, viewed 30April 2018, from https://staff.unisa.ac.za/ static/intranet/Content/Policies/Teaching, $\% 20$ Learning $\% 20$ Community $\% 20$ Engagement $\% 20$ and $\% 2$ Student $\% 20$ Support/Documents/Curriculum $\% 20$
Policy\%20\%20-\%20appr\%20Council\%20-\%2019\%2011\%202010\%20-\%20 rev\%20appr\%20Council\%20-\%2023.11.2012.pdf

Venter, R., 2016, 'Theology and the (post-)apartheid university: Mapping discourses, interrogating transformation', Transformation in Higher Education 1(1), a5. https:// doi.org/10.4102/the.v1i1.5

Vlãsceanu, L., Grünberg, L. \& Pârlea, D., 2004, Quality assurance and accreditation: A glossary of basic terms and definitions, Bucharest, UNESCO-CEPES, Papers on Higher Education, viewed 03 January 2018, from http://www.aic.lv/bolona/ Bologna/contrib/UNESCO/QA\&A\%20Glossary.pdf

Wells, C.A., 2018, 'For such a time and place as this: Christian higher education for the common good', Christian Higher Education 17(1-2), 1-7. https://doi.org/10.1080 /15363759.2017.1419024

Whitelaw, P.A., Henderson, F., Jose, P., Li, D.F., Gao, C.M., Shi, W.J. et al., 2010, Investigating the efficacy of culturally specific academic literacy and academic honesty resources for Chinese students, viewed 30 April 2018, from http://www. ijello.org/Volume9/IJELLOv9p013-027Henderson817.pdf

Wilkinson, S., 2007, The system of nature by baron D'Holbach, Translated from French, viewed 14 July 2013, from http://www.philosophy-index.com/d-holbach/systemnature/ 